\title{
Performance assessment of thick W/Cu graded interlayer for DEMO divertor target
}

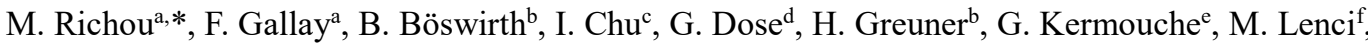

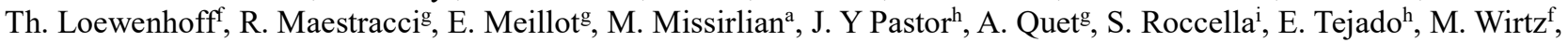
E. Visca ${ }^{\mathrm{i}}$, G. Pintsuk ${ }^{\mathrm{f}}$ and J.H. You ${ }^{\mathrm{b}}$

\author{
${ }^{a}$ CEA, IRFM, F-13108 Saint-Paul-Lez-Durance, France \\ ${ }^{b}$ Max Planck Institute for Plasma Physics, Boltzmann Str. 2, 85748 Garching, Germany \\ ${ }^{c}$ CEA, LITEN, F-38000 Grenoble, France

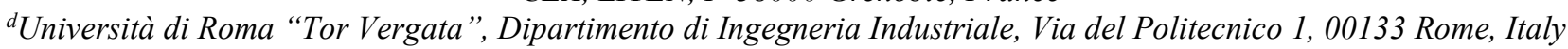

${ }^{e}$ Ecole des Mines de Saint-Etienne, LGF UMR5307 CNRS, 42023 Saint-Etienne, France

${ }^{f}$ Forschungszentrum Jülich, Institute for Energy and Climate Research - Plasmaphysics, Partner of the Trilateral Euregio Cluster (TEC). 52425 Jülich, Germany

${ }^{g}$ CEA, DAM, F-37260 Monts, France

${ }^{h}$ Departamento de Ciencia de Materiales-CIME, Universidad Politécnica de Madrid. C/ Profesor Aranguren 3. E28040-Madrid, Spain.

${ }^{i}$ ENEA, Nuclear Fusion Dept., C. R. Frascati, via E. Fermi 45, 00044 Frascati, Italy

The development of a divertor target for DEMO is of great importance, being able to sustain the harsh environment that is imposed on this component. To fulfill the loading requirements, different concepts were developed within the EUROfusion WPDIV project. The baseline concept is based on the ITER divertor target W-monoblock design. It is made of tungsten as armour material, $\mathrm{CuCrZr}$ as structural material and $\mathrm{Cu}-\mathrm{OFHC}$ as compliant layer. One of the proposed alternative concepts aims to minimize the stress at interfaces by replacing the thick copper interlayer by W/Cu functionally graded material (FGM). In this study, the FGM interlayer, with a thickness of $500 \mu \mathrm{m}$, is composed of stacked elementary layers with the following three compositions: 25 vol. $\% \mathrm{~W}+75 \mathrm{vol} . \% \mathrm{Cu}, 50 \mathrm{vol} \% \mathrm{~W}+50 \mathrm{vol} . \% \mathrm{Cu}, 75 \mathrm{vol} . \% \mathrm{~W}+25$ vol.\% $\%$ u. Several FGM interlayers were studied. In total three monoblock type mock-ups were manufactured. This paper describes the steps needed to manufacture mock-ups and characterization of elementary layers (composition, porosity, Young's modulus). HHF tests applying up to 1000 cycles at $20 \mathrm{MW} / \mathrm{m}^{2}$ and sub-sequent post-mortem examinations were performed to qualify the concept performance.

Keywords: DEMO, Divertor, Plasma-facing component, functional graded material, Non-destructive examinations

\section{Introduction}

For DEMO, the design of the divertor target components is of great importance [1]. The ITER divertor target concept has been determined to be the reference option for DEMO [2]. Accordingly, the component is actively cooled and consists of tungsten (W) as plasma facing material, $\mathrm{CuCrZr}$ as heat sink material and soft $\mathrm{Cu}-\mathrm{OFHC}$ ( $1 \mathrm{~mm})$, which is used as interlayer between $\mathrm{W}$ and $\mathrm{CuCrZr}$ [3]. Requirements for ITER and DEMO divertor target are not fully equivalent since the amount, and therefore the importance, of neutron irradiation significantly increases for DEMO. This is the reason why, within the EUROfusion WPDIV project [1], several divertor target concepts were developed in parallel. One of the concepts proposes to use a functionally graded material (FGM) composed of $\mathrm{W}$ and copper $(\mathrm{W} / \mathrm{Cu})$ as interlayer. Compared to the reference concept, the motivations are to avoid the potential fast fracture of copper under neutron irradiation and to reduce thermal stresses at interfaces [4].

Two possibilities of FGM interlayer thickness were considered during the development: $25 \mu \mathrm{m}$ and $500 \mu \mathrm{m}$. In the case of mock-ups equipped with thin interlayer, PVD (Physical Vapor Deposition) was used to manufacture the continuously graded layer (from $\mathrm{W}$ to $\mathrm{Cu}$ ) of $25 \mu \mathrm{m}$ using tungsten as the base armour material. The joining between the $\mathrm{CuCrZr}$ tube and the $\mathrm{W}$ blocks equipped with the thin graded layer was performed using hot isostatic pressing (HIP) [5] [6]. Mock-ups equipped with thin FGM interlayer showed good performances; however it proved that, for WPDIV project reference geometry, the performance was limited to 130 cycles at $20 \mathrm{MW} / \mathrm{m}^{2}$ [7]. In order to improve the performance of mock-ups with reference geometry by reducing stresses at interfaces, insertion of thick FGM interlayer was proposed. This article describes, from design to high heat flux test qualification, all the results obtained for providing high performance divertor mock-ups equipped with thick FGM interlayer.

\section{Mock-up description}

Each mock-up is constituted of four W blocks as armour material and a $\mathrm{CuCrZr}$ tube as heat sink material. $\mathrm{W}$ and $\mathrm{CuCrZr}$ material properties fulfill the ITER material requirements [5]. They are water-cooled components. The DEMO specifications for the coolant temperature and pressure are $130{ }^{\circ} \mathrm{C}$ and $5 \mathrm{MPa}$, respectively [8]. For the comparison of the concepts developed within WPDIV project, main block dimensions are identical to the ones of other concepts [9]. Consequently, the minimum distance from the interlayer to the plasma-facing surface is $8 \mathrm{~mm}$ [9], block dimensions are $23 \mathrm{~mm}$ (width) $\times$ $27 \mathrm{~mm}$ (height) $\times 12 \mathrm{~mm}($ depth$)$ (Figure 1). The tube inner and outer diameters are 12 and $15 \mathrm{~mm}$, respectively. 
FGM interlayer $(500 \mu \mathrm{m})$ and stacked elementary layer thicknesses were chosen in order to minimize the stresses at interfaces.

a) Sketch

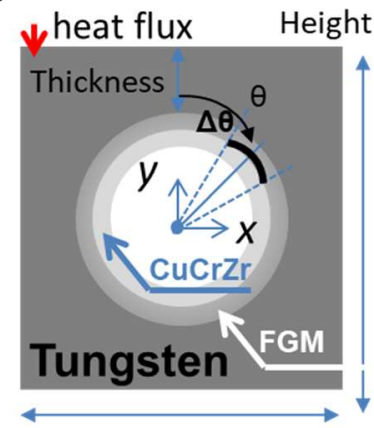

b) Mock-ups

Width

Figure 1: Thick FGM mock-ups: (a) sketch and (b) picture of the three manufactured mock-ups (\#11, \#12 and \#13) with thick FGM

\section{Design and reserve factors}

Monoblock elastic analysis procedure (MEAP) is used to define reserve factors [10]. The obtained results for the studied mock-ups are presented in Table 3. For comparison, results of mock-ups equipped with thin FGM interlayer are recalled [7] in Table 3. For mock-ups with WPDIV project reference geometry (depth of $12 \mathrm{~mm}$, thickness of $8 \mathrm{~mm}$, width of $23 \mathrm{~mm}$ ), reserve factors are higher for mock-ups equipped with thick FGM interlayer and consequently were expected to provide a better performance than those equipped with thin FGM interlayer.

\section{$4 \quad$ Fabrication and examinations}

\subsection{W/Cu elementary layer fabrication and characterization}

Elementary layers, composed of $\mathrm{W}$ and $\mathrm{Cu}$, were manufactured with thermal spray technique (Gas dynamic cold spray) [5]. This industrial coating technique is based on the acceleration of particles within a gas stream and presents the advantage to provide high density materials $(>95 \%)$ and no metal oxidation during the process [11] [12]. During impact with the substrate, particles undergo plastic deformation and adhere to the surface. Process parameters [5] were defined in order to obtain controlled chemical composition and thickness $(500 \mu \mathrm{m})$. Coating chemical compositions were set arbitrarily for this study: $\mathrm{W}$ content of 75 vol. $\%+\mathrm{Cu}$ content of 25 vol. $\%$; W content of 50 vol. $\%+\mathrm{Cu}$ content of $50 \mathrm{vol} . \%$, W content of 25 vol. $\%+\mathrm{Cu}$ content of 75 vol.\%. Porosity and Young's modulus [14] were measured for individually W/Cu deposited layers. The obtained values (Table 1) are higher than those obtained by other manufacturing processes [4]. This difference may be due to the porosity which was $5 \%$ in [4] and $3.1 \%$ in the current study (Table 1).
Table 1: Porosity (\%) and Young's modulus (E in GPa) measured at $20^{\circ} \mathrm{C}$ of elementary layer composed of $\mathrm{W}$ and $\mathrm{Cu}$

\begin{tabular}{cccc}
\hline & $\begin{array}{c}25 \mathrm{vol} . \% \mathrm{~W} \\
+75 \mathrm{vol} . \% \mathrm{Cu} \\
(25 \mathrm{vol} . \% \mathrm{~W})\end{array}$ & $\begin{array}{c}50 \mathrm{vol} . \% \mathrm{~W} \\
+50 \mathrm{vol} . \% \mathrm{Cu} \\
(50 \mathrm{vol} . \% \mathrm{~W})\end{array}$ & $\begin{array}{r}75 \mathrm{vol} . \% \mathrm{~W} \\
+25 \mathrm{vol} . \% \mathrm{Cu} \\
(75 \mathrm{vol} . \% \mathrm{~W})\end{array}$ \\
\hline Porosity & 1.2 & 2.8 & 3.1 \\
$\mathrm{E}$ & 130 & 150 & 160 \\
\hline
\end{tabular}

Table 2: Thicknesses of FGMs (variation of $\pm 15 \mu \mathrm{m}$ )

\begin{tabular}{ccccc}
\hline FGM & $\begin{array}{c}100 \\
\text { vol. } \% \mathrm{Cu} \\
(\mu \mathrm{m})\end{array}$ & $\begin{array}{c}25 \text { vol.\%W } \\
(\mu \mathrm{m})\end{array}$ & $\begin{array}{c}50 \text { vol.\%W } \\
(\mu \mathrm{m})\end{array}$ & $\begin{array}{c}75 \text { vol.\%W } \\
(\mu \mathrm{m})\end{array}$ \\
\hline $25 \_1$ & 25 & 445 & - & - \\
$25 \_2$ & 65 & 405 & - & - \\
$50 \_1$ & 25 & 220 & 225 & - \\
$50 \_2$ & 65 & 200 & 205 & - \\
$75 \_1$ & 65 & 135 & 135 & 135 \\
\hline
\end{tabular}

\subsection{FGM interlayer}

The thick FGM tube was chosen to be constituted of stacked elementary layers. Each of them was manufactured as described in 4.1. In the following, the nomenclature for each of the $\mathrm{W} / \mathrm{Cu}$ layer will be reduced to their $\mathrm{W}$-content, e.g. $25 \mathrm{vol} . \% \mathrm{~W}$ for a layer composed of $25 \mathrm{vol} . \% \mathrm{~W}+75 \mathrm{vol} . \% \mathrm{Cu}$. The first layer of the coating $(25$ vol. $\% \mathrm{~W})$ was applied on a cylindrical $\mathrm{Cu}$ substrate. Each subsequent layer was coated onto the previous layer. The product was then machined and the cylindrical $\mathrm{Cu}$ substrate almost fully removed in order to form a free standing layer in tube shape.

Considering the $\mathrm{W}$ particle size $(\mathrm{D} 90=16 \mu \mathrm{m})$ and the number of layers to achieve the FGM, a reasonable minimum elementary layer thickness was set at $130 \mu \mathrm{m}$. To produce a total FGM interlayer thickness of $500 \mu \mathrm{m}$, a maximum of three elementary stacked layers was consequently set. For mock-up performance assessment, influence of the number of stacked layers constituting the FGM interlayer was studied. The related thicknesses and chemical composition are presented in Table 2. For example, the FGM interlayer referenced as 50_2, is composed of a 50 vol. $\% \mathrm{~W}$ layer $(205 \mu \mathrm{m})$ coated on a 25 vol. $\% \mathrm{~W}$ layer $(200 \mu \mathrm{m})$. An optical micrograph of this FGM interlayer is presented in Figure 2. After FGM manufacturing, the maximum difference between required and measured composition and thickness for all elementary layers is $7 \mathrm{vol} . \%$ and $15 \mu \mathrm{m}$ respectively.

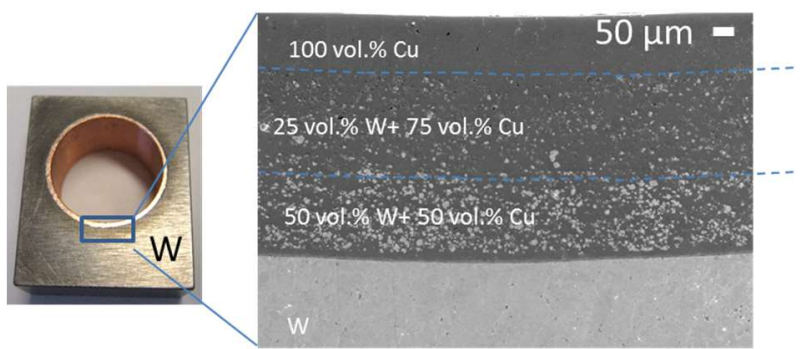

Figure 2: W block with FGM at its internal part and corresponding FGM 50_2 configuration observed with scanning electron microscope 
Table 3. Geometries, material grade and MEAP results for manufactured mock-ups

\begin{tabular}{|c|c|c|c|c|c|c|c|c|c|c|c|}
\hline \multirow{2}{*}{ Mock-up type } & \multicolumn{4}{|c|}{$\mathrm{W}$ dimensions/ $\mathrm{mm}$} & \multirow{2}{*}{$\begin{array}{l}\text { Interlayer thickness / } \\
\qquad \mu \mathrm{m}\end{array}$} & \multirow{2}{*}{$\begin{array}{c}\mathrm{CuCrZr} \\
\text { external } \\
\text { diameter / } \\
\mathrm{mm}\end{array}$} & \multirow{2}{*}{$\begin{array}{l}\text { Pipe } \\
\text { ratchetting }\end{array}$} & \multirow{2}{*}{$\begin{array}{c}\text { Pipe } \\
\text { fatigue } \\
(6000 \\
\text { cycles }) \\
\end{array}$} & \multirow{2}{*}{$\begin{array}{c}\text { Pipe } \\
\text { max. temp. } \\
\left(350^{\circ} \mathrm{C}\right)\end{array}$} & \multirow{2}{*}{$\begin{array}{c}\text { Wall peak } \\
\text { heat flux } \\
(44.4 \\
\left.\mathrm{MW} / \mathrm{m}^{2}\right)\end{array}$} & \multirow{2}{*}{$\begin{array}{c}\text { Armor Max. } \\
\text { Temp. } \\
\left(1800^{\circ} \mathrm{C}\right)\end{array}$} \\
\hline & $\begin{array}{c}\text { Thickn } \\
\text { ess }\end{array}$ & Width & Height & Depth & & & & & & & \\
\hline \multirow{2}{*}{ Thin FGM [7] } & 5 & 22 & 23 & 4 & 25 & 14 & 0.68 & 2.04 & 1.3 & 3.1 & 2.2 \\
\hline & 8 & 23 & 26 & 12 & 25 & 15 & 0.61 & 1.18 & 1.1 & 2.1 & 1.4 \\
\hline Thick FGM & 8 & 23 & 27 & 12 & 500 & 15 & 0.87 & 1.68 & 1.1 & 2.8 & 1.6 \\
\hline
\end{tabular}

\subsection{Mock-up manufacturing}

After the realization of the FGM tube, a first HIP cycle was applied $\left(1000^{\circ} \mathrm{C}, 1400\right.$ bars during $\left.2 \mathrm{~h}\right)$ to join FGM tube to $\mathrm{W}$ blocks. After machining, individual W blocks with FGM at the internal part were obtained (Figure 2). Then the second HIP cycle $\left(1000^{\circ} \mathrm{C}, 1400\right.$ bars during $\left.2 \mathrm{~h}\right)$ was realized to join the $\mathrm{CuCrZr}$ tube. In total, 3 mock-ups (namely \#11,\#12 and \#13) were manufactured (Figure 1). The FGM interlayer types for the different mock-ups and blocks are presented in Table 4.

Table 4: FGM interlayer types for the different mock-ups

\begin{tabular}{ccccc} 
Mock-up & 1 & 2 & 3 & 4 \\
\hline 11 & $25 \_1$ & $50 \_1$ & $50 \_1$ & $25 \_1$ \\
$\# 12$ & $25 \_2$ & $50 \_2$ & $50 \_2$ & $25 \_2$ \\
$\# 13$ & $25 \_2$ & $75 \_1$ & $75 \_1$ & $25 \_2$ \\
\hline
\end{tabular}

\subsection{Non-destructive tests after manufacturing}

Non-destructive examinations (NDE) (Ultrasonic tests (UT) and global thermal assessment test with SATIR facility [16]) are performed to detect possible thermal imperfection at the different interfaces (quantified by the extension $(\Delta \theta)$ and the position $(\theta)$ ) [17] (Figure 1).

Detected defects are presented in Table 5 . No defect was observed after fabrication for $100 \%$ of blocks constituted with $251,252,502$ interlayers. While $50 \%$ of the blocks constituted with $50 \_1$ interlayer had no defect and $100 \%$ of the blocks constituted with $75 \_1$ interlayer had defect. Defects were detected with both techniques. They are $360^{\circ}$ extension and located at FGM interlayer to $\mathrm{W}$ interface. To confirm these NDE results, mock-up\#13 was cut and block \#2 was observed with Scanning Electron Microscope (Figure 3). A $360^{\circ}$ crack localized at $\mathrm{W}$ to FGM interlayer interface, which propagates within 75 vol.\%W layer, is observable. For this reason, for future mock-ups manufactured with the current manufacturing process, the integration of 75_1 FGM interlayer will be avoided.

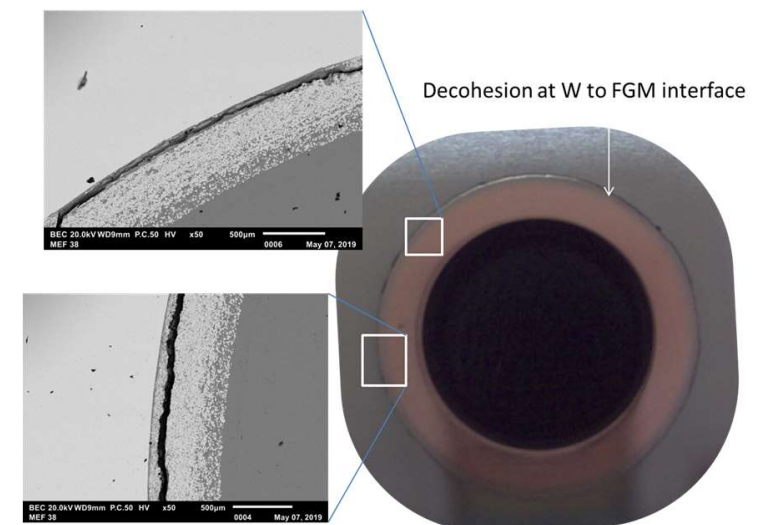

Figure 3: Decohesion of $\mathrm{W}$ block to FGM after fabrication (Mock-up \#13 block \#2)

Table 5: Defects (marked with a cross) detected before and/or after high heat flux tests

\begin{tabular}{|c|c|c|c|c|c|}
\hline \multirow{2}{*}{ Mock-up } & & \multicolumn{4}{|c|}{ Blocks } \\
\hline & & 1 & 2 & 3 & 4 \\
\hline \multirow[t]{2}{*}{$\# 11$} & Before & & $\mathrm{x}$ & & \\
\hline & After & & HHF & $\mathrm{x}$ & \\
\hline \multirow[t]{2}{*}{$\# 12$} & Before & & & & \\
\hline & After & & & & \\
\hline \multirow[t]{2}{*}{$\# 13$} & Before & & $\mathrm{x}$ & $\mathrm{x}$ & \\
\hline & After & \multicolumn{4}{|c|}{ No HHF } \\
\hline
\end{tabular}

\subsection{High heat flux tests}

Thermal heat exhaust capability is checked with cyclic high heat flux (HHF) testing. Thereby, one cycle consists of $10 \mathrm{~s}$ of heat loading to obtain steady state conditions in the mock-up followed by $10 \mathrm{~s}$ dwell time. Due to the position of the defect within mock-up \#13, this block was not part of the HHF test campaign. From mock-up \#11, blocks \#3 and \#4 were tested with cold water cooling $\left(70^{\circ} \mathrm{C}, 30 \mathrm{bar}, 12 \mathrm{~m} / \mathrm{s}\right)$ in the JUDITH-2 facility [18]. Block \#3 was tested up 972 cycles at $20 \mathrm{MW} / \mathrm{m}^{2}$ and block \#4 up to 1000 cycles at $20 \mathrm{MW} / \mathrm{m}^{2}$ followed by 10 cycles at $23.5 \mathrm{MW} / \mathrm{m}^{2}$. During loading at $20 \mathrm{MW} / \mathrm{m}^{2}$ a surface temperature of $2500^{\circ} \mathrm{C}$, measured with two-color pyrometer [5], was reached. For Block \#3, after the 972nd cycle an overheating was noticed $\left(2700^{\circ} \mathrm{C}\right.$ measured by Infrared camera) so that the cycling was stopped. During cooling down of this block, the characteristic cool-down time was measured. An effect of HHF tests was noticed (806 $\mathrm{ms}$ before the cycling and $1825 \mathrm{~ms}$ after the occurrence of overheating), meaning that power handling was reduced due to HHF tests. No overheating was noticed during the heat loading of block \#4. The limit in 
terms of imposed heat load $\left(23.5 \mathrm{MW} / \mathrm{m}^{2}\right)$ was due to the significant surface temperature measured by the twocolor pyrometer $\left(3200^{\circ} \mathrm{C}\right)$. No modification of the power handling performance was noticed for this block, since the characteristic cool-down time was the same before and after the completion of the cycling (i.e $699 \mathrm{~ms}$ before and $710 \mathrm{~ms}$ after).

The remaining mock-up \#12 was HHF tested in the GLADIS facility [19]. HHF test condition consisted, as for the other concepts tested in the frame of the WPDIV project, in performing 500 cycles at $20 \mathrm{MW} / \mathrm{m}^{2}$ under hot water cooling conditions $\left(130{ }^{\circ} \mathrm{C}, 40 \mathrm{bar}, 16 \mathrm{~m} / \mathrm{s}\right)$ [5]. During the HHF testing campaign, no damage was observed since no overheating was noticed. The infrared picture of the last cycle performed at $20 \mathrm{MW} / \mathrm{m}^{2}$ is presented in Figure 4. The surface temperature $\left(2400^{\circ} \mathrm{C}\right)$ was in the same range as the one obtained during the HHF testing performed in the JUDITH-2 facility. The behaviour observed during HHF tests is in total agreement with the results from the NDE.

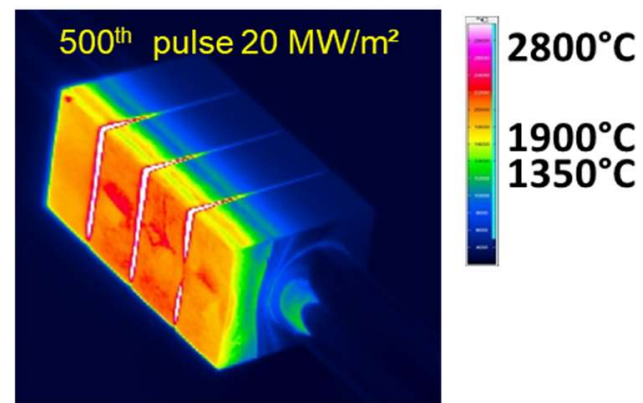

Figure $4:$ Infrared picture from high heat flux tests (latest cycle at $20 \mathrm{MW} / \mathrm{m}^{2}$ ) of mock-up\#12

\subsection{The integrity of mock-ups after HHF tests}

NDEs (SATIR and UT) were performed after HHF tests. Detected defects are presented in Table 5. Only one measurable defect, located on block \#3 on mock-up \#11, was generated during $\mathrm{HHF}$ test $\left(\theta=5^{\circ}\right.$ and $\Delta \theta=170^{\circ}$ measured by SATIR and $\theta=5^{\circ}$ and $\Delta \theta=150^{\circ}$ measured by UT). Metallographic examination revealed decohesion between $\mathrm{W}$ to FGM interface $\left(\theta=5^{\circ}\right.$ and $\left.\Delta \theta=150^{\circ}\right)$ (Figure 5). Defect size is consistent with NDE results. Propagation of the crack within $50 \mathrm{vol} \%$.W layer is observed. Two cracks $(800 \mu \mathrm{m})$ are located at W/FGM interface and propagate within $\mathrm{W}$ block. Decohesion between $25 \mathrm{vol} \%$.W to $100 \mathrm{vol} \%$.Cu layers is observed. It was detected at the $\mathrm{W}$ to FGM interlayer interface. This block should be analyzed with metallographic examination in the future to understand the failure reason. Global picture of the mock-up \#12 block \#1 is presented in Figure 6. This HHF loaded block (500 cycles at 20 $\mathrm{MW} / \mathrm{m}^{2}$ ) was classified as non-damaged with regard to results obtained during HHF tests and with NDE. For this block, 25_2 FGM interlayer is implemented. This block does not show any $\mathrm{W}$ surface modification nor crack formation at interfaces or in $\mathrm{CuCrZr}$ (Figure 6). HHF test conditions were the same for the block \#2 of the same mock-up. For this block, 50_2 FGM interlayer is implemented. The interface integrity was also emphasized after HHF tests (Figure 6). Considering FGM interlayer thickness after mock-up manufacturing and HHF tests, one can note a maximum difference of $24 \%$ with regard to the ones measured after the coating process. This difference may be due to HIP process, which decreases material thickness by diffusion process occurring during pressure loading.

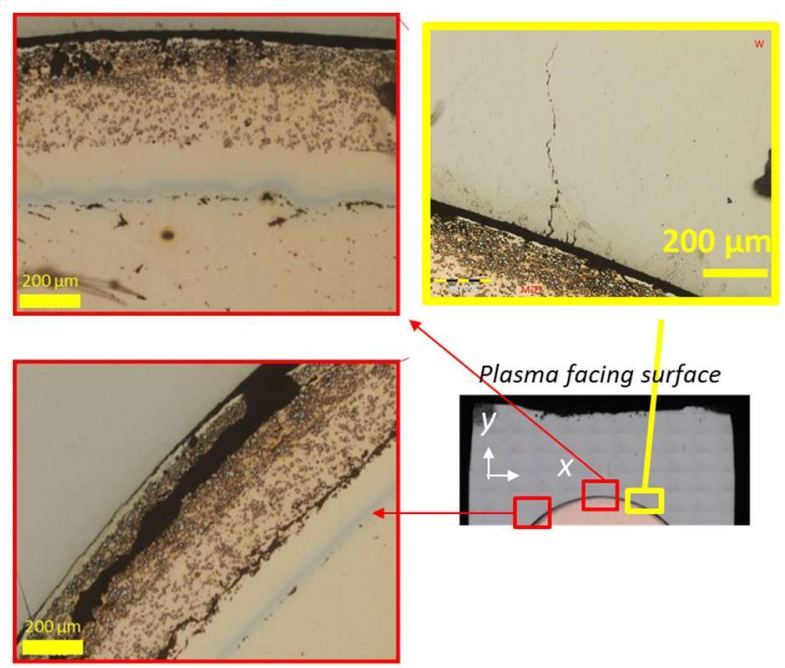

Figure 5: Mock-up \#11 block \#3 equipped with thick FGM interlayer (50_1) after 972 cycles at $20 \mathrm{MW} / \mathrm{m}^{2}$ and cutting preparation: Decohesion at $\mathrm{W}$ to $\mathrm{FGM}$ interface (upper left) crack from W/FGM interface to $\mathrm{W}$ block (upper right) Decohesion between $25 \mathrm{vol} \%$.W to 100 vol $\% . \mathrm{Cu}$ layer and propagation of crack within 50 vol\%.W layer (lower left)
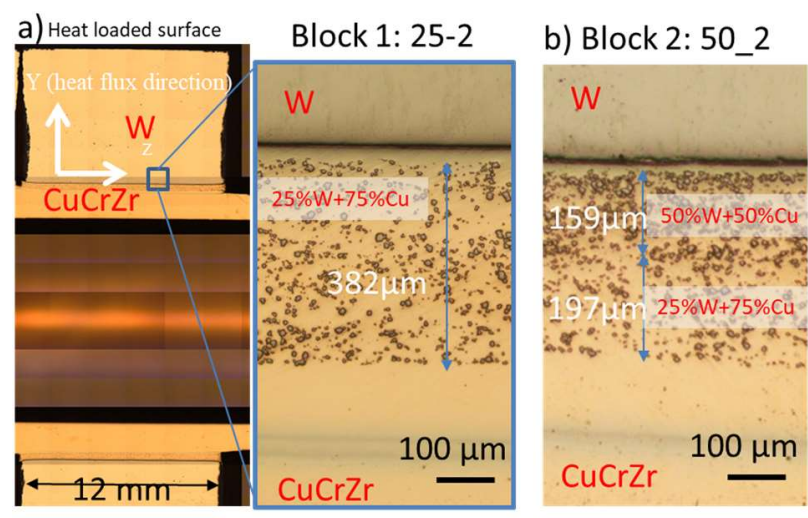

Figure 6: Images of mock-up \#12 equipped with thick FGM interlayer after 500 cycles at $20 \mathrm{MW} / \mathrm{m}^{2}$ and cutting preparation: block \#1 (a) block \#2 (b)

\section{Summary and conclusions}

For DEMO divertor target, one concept uses W/Cu graded material (FGM) as interlayer between $\mathrm{W}$ armor material and $\mathrm{CuCrZr}$ tube. FGM interlayer, with a total nominal thickness of $500 \mu \mathrm{m}$ and constituted of a maximum of three elementary stacked layers composed of $\mathrm{W}$ and $\mathrm{Cu}$, were successfully manufactured. Indeed, after FGM manufacturing, the required FGM thicknesses and compositions $(25$ vol. $\% \mathrm{~W}+75$ vol. $\% \mathrm{Cu}, 50$ vol. $\% \mathrm{~W}+$ 50 vol. $\% \mathrm{Cu}, 75$ vol. $\% \mathrm{~W}+25$ vol. $\% \mathrm{Cu}$ ) were achieved within variations of $7 \%$ and $\pm 15 \mu \mathrm{m}$ respectively. To manufacture mock-ups, two HIP cycles were applied: the 
first one to join W block to FGM tube interlayer, the second one to join $\mathrm{CuCrZr}$ tube. No defect was observed after fabrication for $\sim 75 \%$ of the blocks. Defects detected by NDE were located at W to FGM interlayer interface in particular for FGMs comprising all three elementary compositions. Accordingly, it was decided to focus the HHF testing on mock-ups equipped with FGM interlayer constituted of only one layer (composed of $25 \mathrm{vol} \% \mathrm{~W}+$ $75 \mathrm{vol} . \% \mathrm{Cu}$ ) or two layers (composed of $25 \mathrm{vol} . \% \mathrm{~W}+$ 75 vol.\% $\mathrm{Cu}$ and 50 vol.\% $\mathrm{W}+50$ vol.\% Cu). Mock-ups showed good high heat flux performances by providing identical results for all the investigated compositions and thicknesses sustaining up to 500 cycles at $20 \mathrm{MW} / \mathrm{m}^{2}$. Selected blocks were tested up to a maximum of 1000 cycles at $20 \mathrm{MW} / \mathrm{m}^{2}$ followed by 10 cycles at $23.5 \mathrm{MW} / \mathrm{m}^{2}$. The integrity of $\mathrm{W}$, FGM interlayer, $\mathrm{CuCrZr}$ and material interfaces after 500 cycles at $20 \mathrm{MW} / \mathrm{m}^{2}$ lead to conclude that thick FGM interlayer, composed of $\mathrm{W}$ and $\mathrm{Cu}$, have positive potential for DEMO divertor application since that these mock-ups showed no damage and that the graded interlayer could exhibit benign irradiation behavior without drastic embrittlement as pure copper shows.

\section{Acknowledgments}

This work has been carried out within the framework of the EUROfusion Consortium and has received funding from the Euratom research and training programme 20142018 and 2019-2020 under grant agreement No 633053. The views and opinions expressed herein do not necessarily reflect those of the European Commission.

\section{References}

[1] J.H. You et al., European DEMO divertor target: Operational requirements and material design interface, Nuclear Materials and Energy 000 (2016) 1-6

[2] M. Merola et al., ITER plasma-facing components, Fusion Eng. Des. 85 (2010) 2312-2322.

[3] E. Visca et al., Manufacturing and testing of ITER-like divertor plasma facing mock-ups for DEMO, Fusion Eng. Des. 136 (2018) 1593-1596.

[4] G. Pintsuk et al., Development of W/Cu-functionally graded materials, Fusion Eng. Des.66-68 (2003) 237-240

[5] M. Richou et al., Realization of high heat flux tungsten monoblock type target with graded interlayer for application to DEMO divertor, Phys. Scrip. T170 (2017) 014022 (7pp).

[6] M. Richou et al., Status on the W monoblock type high heat flux target with graded interlayer for application to DEMO divertor, Fusion Eng. Des. 124 (2017) 338-343.

[7] M. Richou et al., Performance assessment of high heat flux W monoblock type target using thin graded and copper interlayers for application to DEMO divertor, Fusion Eng. Des. 146 (2019) 858-861.

[8] J.H. You et al., European divertor target concepts for DEMO: Design rationales and high heat flux performance, Nuclear Materials and Energy, vol. 16, pp. 1-11, 2018.

[9] J.H. You et al., Conceptual design studies for the European DEMO divertor: Rationale and first results, Fusion Eng. Des.109-111 (2016) 1598-1603

[10] Th. Barrett et al., Progress in the engineering design and assessment of the European DEMO first wall

and divertor plasma facing components, Fusion Eng. Des. 109111 (2016) 917-924.
[11] S. Barradas et al., Application of laser shock adhesion testing to the study of the interlamellar strength and coatingsubstrate adhesion in cold-sprayed copper coating of aluminum, Surface \& Coatings Technology 197 (2005) 18- 27

[12] Hyun-Ki Kang et al., Tungsten/copper composite deposits produced by a cold spray, Scripta Materialia 49 (2003) 11691174

[13] J. Hartmann et al., High Temperatures-High Pressures 25 (1993) 403-410.

[14] Nuevas técnicas para la caracterización mecánica de recubrimientos obtenidos mediante proyección en frío (Cold Spray), Sandra Tarancón Master Thesis, Universidad Nacional de Educación a Distancia (UNED), Spain

[15] M. Galatanu et al 2018 Mater. Res. Express 5026502

[16] M. Richou et al., Effect of induction heating on flaw generation and expansion, Fusion Eng Des. 136 (2018) 12731277.

[17] F. Gallay et al., Quantitative thermal imperfection definition using non-destructive infrared thermography on an advanced DEMO divertor concept Phys. Scrip. T170 (2017) 014015 (5pp).

[18] P. Majerus, R.,Duwe, T.Hirai, W. Kühnlein, J. Linke and M. Rödig (2005) Fusion Eng. Des. 75-79, 365-369

[19] H. Greuner et al., Progress in high heat flux testing of European DEMO divertor mock-ups, Fusion Eng Des. 146 (2019) 216-219. 